D) Check for updates

Cite this: RSC Adv., 2017, 7, 35251

DOI: $10.1039 / c 7 r a 90081 c$

www.rsc.org/advances

\section{Correction: One-step synthesis of composite material MWCNTaBiVO 4 and its photocatalytic activity}

Deqiang Zhao, ${ }^{\text {ae }}$ Wenwen Wang, ${ }^{\text {b }}$ Yaofang Sun, ${ }^{\text {ad }}$ Zihong Fan, ${ }^{c}$ Mao Du, ${ }^{\text {ae }}$ Qian Zhang, ${ }^{\text {ad }}$ Fangying Ji ad and Xuan $\mathrm{Xu}^{* a e}$

Correction for 'One-step synthesis of composite material $\mathrm{MWCNTABiVO}_{4}$ and its photocatalytic activity' by Deqiang Zhao et al., RSC Adv., 2017, 7, 33671-33679.

The Acknowledgement section should be modified as shown below:

Financial support from the Science and Technology Innovation Special Projects of Social Undertakings and Livelihood Support, Chongqing (cstc2016shmszx20009), the Science and Technology Project of Chongqing Education Commission (KJ1500604), the graduate scientific research and innovation foundation of Chongqing, China (CYB16008), the Chongqing Research Program of Basic Research and Frontier Technology (cstc2015jcyjA20013, cstc2017jcyjBX0080) and the 111 Project (B13041) is gratefully acknowledged.

The Royal Society of Chemistry apologises for these errors and any consequent inconvenience to authors and readers.

\footnotetext{
${ }^{a}$ Key Laboratory of Three Gorges Reservoir Region's Eco-Environment, Ministry of Education, Chongqing University, Chongqing 400067, China. E-mail: xuxuan@cqu.edu.cn ${ }^{b}$ Faculty of Urban Construction \& Environment Engineering, Chongqing 400045, China

${ }^{\prime}$ School of Environmental and Biological Engineering, Chongqing Technology and Business University, Chongqing 400067, China

${ }^{d} J o i n t$ International Research Laboratory of Green Buildings and Built Environments, Ministry of Education, Chongqing University, Chongqing 400045, China

${ }^{e}$ National Centre for International Research of Low-carbon and Green Buildings, Chongqing University, Chongqing 400045, China
} 